\title{
30
}

\section{Considerations for future education in integrative landscape research}

\author{
Gunther Tress ${ }^{1}$, Bärbel Tress ${ }^{1}$, Gary Fry², Paul Opdam ${ }^{3}$, Jack Ahern ${ }^{4}$, \\ Marc Antrop, ${ }^{5}$ Terry Hartig ${ }^{6}$, Richard Hobbs ${ }^{7}$, David Miller ${ }^{8}$, \\ Janet Silbernagel $^{9}$, Nick Winder ${ }^{10}$
}

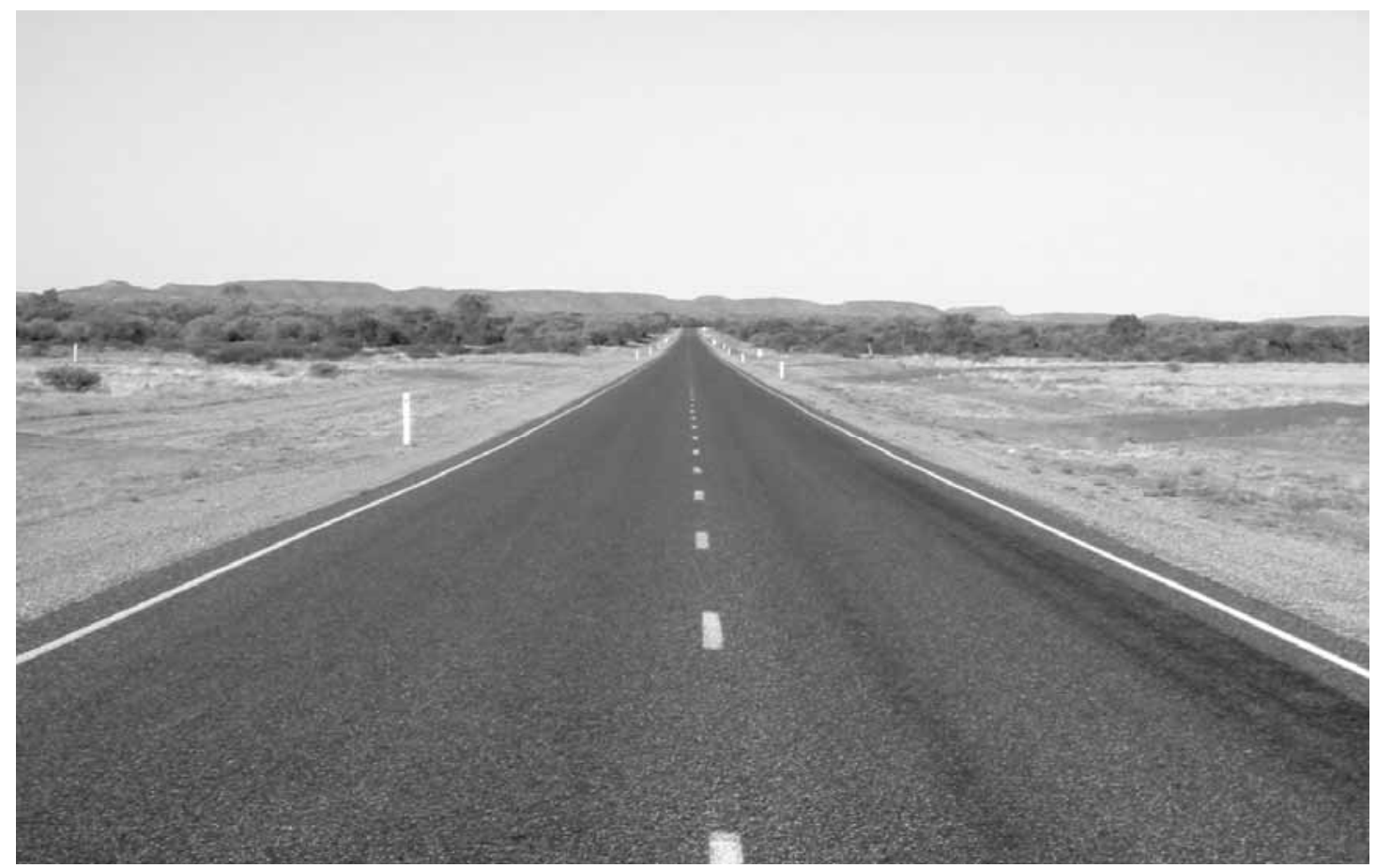

\footnotetext{
${ }^{1}$ Land Use Planning Group, Department of Environmental Sciences, Wageningen University, Generaal Foulkesweg 13, 6703 BJ Wageningen, The Netherlands. E-mail: tress@tress.cc, http://www.tress.cc

${ }^{2}$ Institute of Landscape Planning, Norwegian University of Life Sciences, P.O. Box 5029, N-1432 Ås, Norway. E-mail: gary.fry@umb.no

${ }^{3}$ Land Use Planning Group, Department of Environmental Sciences, Wageningen University, Generaal Foulkesweg 13, 6703 BJ Wageningen, The Netherlands. E-mail: Paul.Opdam@wur.nl

${ }^{4}$ Department of Landscape Architecture and Regional Planning, University of Massachusetts, Amherst, MA 01003, USA. E-mail: jfa@larp.umass.edu

${ }^{5}$ Geography Department, Ghent University, Krijgslaan 281 S8, B-9000 Ghent, Belgium. E-mail: marc.antrop@ugent.be

${ }^{6}$ Institute for Housing and Urban Research, Uppsala University, Box 785, S-801 29 Gävle, Sweden. E-mail: Terry.Hartig@ibf.uu.se

${ }^{7}$ School of Environmental Science, Murdoch University, Murdoch, WA 6150, Australia. E-mail: rhobbs@murdoch.edu.au

8 Macaulay Institute, Craigiebuckler, Aberdeen AB15 8QH, United Kingdom. E-mail: d.miller@macaulay.ac.uk

${ }^{9}$ Department of Landscape Architecture, University of Wisconsin, Room 12, Agriculture Hall, 1450 Linden Dr., Madison, WI 53706 USA. E-mail: jmsilber@wisc.edu

${ }^{10}$ School of Historical Studies, University of Newcastle-upon-Tyne, Newcastle upon Tyne NE1 7RU, United Kingdom. E-mail: tigress@ncl.ac.uk
} 


\begin{abstract}
This chapter discusses challenges for $\mathrm{PhD}$ students involved in integrative landscape research. These challenges include terminology, epistemology, expectations, stakeholder involvement, organizational barriers, communicating and publishing, as well as career development. The chapter presents recommendations for future integrative landscape research involving $\mathrm{PhD}$ students and prospects for future education. The recommendations are based on our experiences in research and teaching in general, and on our exchanges with the students in the PhD master class in particular. The recommendations also reflect on the conclusions that can be drawn from the PhD students' contributions in this book.
\end{abstract}

Keywords: interdisciplinary; transdisciplinary; research training; barriers to integration; discipline-oriented organization

\title{
Introduction
}

In the introduction to this book Tress et al. (2005) identified six key challenges for PhD students in integrative landscape research. These challenges included: defining concepts related to integrative research, coping with epistemological differences across knowledge cultures, coping with high expectations of the results and products of integrative research, involving stakeholders and the general public in the research, overcoming organizational barriers, and communicating and publishing the findings of the research. In addition to these six challenges, further difficulties and problems emerged during the $\mathrm{PhD}$ master class. The aim of this final chapter is to summarize and discuss these challenges. The chapter presents recommendations for future integrative landscape research involving PhD students, and discusses the prospects for future $\mathrm{PhD}$ education. The recommendations are based on the combined experiences of the staff and students present at the PhD master class and also reflect conclusions that can be drawn from the written contributions of the PhD students in this book. The statements of $\mathrm{PhD}$ students quoted in this chapter derive from the students' evaluation of the course.

\section{Defining common language, terminology and concepts}

Individual researchers have difficulties communicating when terminology is not consistently defined within a research group. The communication process in an integrative research group demands a common language. Concepts such as interdisciplinarity and transdisciplinarity seem particularly important. Individual students at the $\mathrm{PhD}$ master class attached different meanings to these concepts and so expressed different expectations towards them. Not surprisingly, it was difficult for an individual student to fully understand the way fellow students used concepts. Similar observations can be made for other terms and concepts and their meaning may even change over a certain period of time and in certain contexts. For instance, the study by Jensen (2005) presented in this book exemplifies the changing meaning of the landscape concept in landscape assessment methods in England.

Whereas the individual researcher can usually develop a structured terminology and define its content for the individual use in her/his project, the problems increase when working at the level of the research community. How can research concepts be applied, evaluated and discussed properly when their meaning varies and common explanations are lacking? Terminological and conceptual vagueness create 
communication problems and underpin contrasting expectations in respect of integration. A lack of common understanding also limits common learning about benefits and drawbacks of the concepts.

The integration concept is not merely a research concept, bringing scientific knowledge cultures together. It is also used for integrating different sectors such as science and management, planning and policy or water, soil and climate. The chapters by Ferreira and Leitão (2005), Gontier (2005) and Swagemakers and Wiskerke (2005) give examples of such a broader conception of integration. We recommend drawing more attention to the different interpretations of integrative concepts used in research or as a way of expressing the interrelationship of different land-use or management sectors such as water, soil and climate or planning and policy.

At the PhD master class, confusion about integrative research concepts and their meanings came to the fore during discussions in subgroups and in plenary sessions. We recognized a demand for clarification, demystification and firming-up of integrative research concepts. Clarification of these concepts might help the PhD students to set realistic goals for their own project, without losing the integrative potential of the study. The chapter by Tveit (2005) successfully demonstrates this. Clarification of concepts helps the students to identify the most appropriate approach for their study, even if this may lead to choosing deliberately not to follow an integrative approach as one student did after the $\mathrm{PhD}$ master class: "I will make some major changes in the aims of my project and actually I am going to make it a disciplinary study (based on the advice that I was given in the tutorials)". We, therefore, recommend that $\mathrm{PhD}$ students clearly define the meaning of integrative research concepts in their respective projects and make this understanding explicit in publications and presentations.

\section{Epistemological differences across knowledge cultures}

Almost all of the PhD students observed the epistemological differences that exist across the different knowledge cultures of, for instance, natural sciences, social sciences and humanities as a key problem for integration. $\mathrm{PhD}$ students are highly motivated to integrate different knowledge cultures in their studies in order to provide new insights on research problems, but they, and often their more senior colleagues, suffer from a lack of readily applicable theoretical and methodological instruments for approaching integration. Consequently, most $\mathrm{PhD}$ students fall back on existing theories and concepts from one knowledge culture and try to apply these to other knowledge cultures. Some PhD students choose a different path, and experiment with new theories and methods that have not been fully developed or tested. These difficulties are addressed in several of the student papers. The chapter by Queiroz (2005) illustrates the epistemological and methodological barriers that need to be overcome when integrating natural sciences with humanities in order to present complementary versus alternative knowledge derived from different knowledge cultures. A good example for the development of common theory for integrative research based on the holistic concept of landscape is the chapter by Ruiz and Domon (2005). They illustrate a conceptual approach to overcome epistemological barriers between natural sciences, social sciences and humanities. Also the papers from Drewes and Silbernagel (2005), Gontier (2005), Immink (2005), Lewis (2005) and Macpherson (2005) address epistemological difficulties in their contributions.

There is no shortcut to integration and overcoming epistemological differences. The only way we find to cope with this difficulty is to get inside other knowledge 
cultures. Trying to understand the concepts, theories, methods and value systems used in other disciplines helps to bridge between knowledge cultures. Exchanging, discussing and reading each other's publications helps as well as searching for common denominators on which to base integration. One student at the course framed these learning experiences in this way: "When I first saw the (course) program I felt a little disappointed: only student and teacher presentations. ... Then I realized that you can learn so much from each other's work and experience, so it was really fruitful to hear all the other projects". Another student added: "It made me realize where the weak points of my $\mathrm{PhD}$ are, it helped me to frame my project. It helped to develop critical reading and thinking about other projects”.

\section{Involving stakeholders and the general public}

An increasing number of $\mathrm{PhD}$ projects involve stakeholders such as planning authorities, locals or land managers or the general public. The chapters by Barthel (2005), Drewes and Silbernagel (2005), Ferreira and Leitão (2005), Immink (2005), McNamara (2005), Nimmo (2005) and Sauer (2005) provide evidence for the increasing influence of transdisciplinary aspects in the PhD studies. However, the role that stakeholders play in the project is not always defined and sometimes stakeholders' influence has a serious impact on the course of the $\mathrm{PhD}$ project. We have seen projects where stakeholders take over control of the project to achieve their goals, which may not be in agreement with the student's wishes or the formal requirements for the $\mathrm{PhD}$. Roles to be distinguished are client (having a stake in using the results for solving a local problem), coach (learn the student how to interact with practical problems) and advisor (tell the student about problems to be solved in the context of the PhD project). The first role may be conflicting with the scientific goals of the project. We recommend supervisors, $\mathrm{PhD}$ students and funding bodies to make clear agreements with stakeholders about their role and the expectations they can place on their involvement in the PhD project. Equally, those responsible for raising funds, for which increased involvement of end-users is seen as desirable or a prerequisite, have a responsibility for negotiating a level of participation that is of value to all parties.

\section{Coping with high expectations}

Coping with unrealistically high expectations - for oneself, one's project, and one's more senior colleagues - can be a serious problem for $\mathrm{PhD}$ students. Besides the research objectives, more and more $\mathrm{PhD}$ projects in integrative landscape research involve applied components that aim to solve real-world problems. $\mathrm{PhD}$ projects in the area tend to operate at the interfaces between science and management or science and policy. Research is conducted either to stimulate or support a certain policy, and projects therefore have a clear focus on application and implementation of research results. The chapters by Ferreira and Leitão (2005), Lewis (2005), McNamara (2005), Pacha (2005) and Pixova and Sklenicka (2005) are examples of studies with strong applied components. These tasks are of course a strong stimulus for the PhD students to conduct an integrative study. We believe that scientific innovation is challenged by the need to solve practical problems, but solving the problem should not be the dominant goal of the PhD project. It can only be an additional task for the PhD students because they need to fulfil also the requirements for a $\mathrm{PhD}$, which include scientific advancement, conducting transparent and independent research, and 
scientific publishing. Several of the $\mathrm{PhD}$ students at the $\mathrm{PhD}$ master class had these additional applied or policy-related tasks included in their projects, but it remained unclear to us how well this extensive set of additional tasks could be realized in a single PhD study. Also the question is left open whether these goals are set on top of the regular expectations towards a PhD study or whether they should substitute goals such as scientific advancement and publishing. As long as there is any uncertainty about the goal-setting and requirements of a $\mathrm{PhD}$ in integrative research, the criteria for evaluating the transdisciplinary and solution-oriented efforts are unclear. However, to evaluate the efforts made in fulfilling additional tasks as described above, explicit criteria would be necessary.

Although many departments do have formal requirements in this regard, we nonetheless think it worth recommending here that $\mathrm{PhD}$ students and their supervisors review the goals defined for the $\mathrm{PhD}$ project in the light of the available time, resources and personal capacity of the student. From the student's perspective, reaching more than was anticipated at the outset will be more motivating over the course of the project than knowing that there is no chance of even coming close to what was expected. Funding bodies of $\mathrm{PhD}$ studies also need to be informed about the consequences of excessively high expectations.

When choosing an integrative approach for a $\mathrm{PhD}$ study we recommend making integration an aim itself and not only to regard it as a means to an end. PhD students who can demonstrate successful integration of knowledge cultures in their projects have already contributed substantially to further developing integrative landscape research, and this achievement should be acknowledged.

\section{Overcoming organizational barriers}

Organizational barriers can be a significant influence on the progress and success of an integrative $\mathrm{PhD}$ project. The experiences of the $\mathrm{PhD}$ students at the $\mathrm{PhD}$ master class revealed a great variety of organizational and institutional barriers that make life as an integrative $\mathrm{PhD}$ student difficult.

A key barrier is the organizational and discipline-oriented structure of the host institute that determines the everyday life of a PhD student (see EURAB 2004). Research, teaching and social interactions at many institutes are disciplinary in their organization. Integrative research projects may challenge or threaten the traditional disciplinary orientation of academic institutes. $\mathrm{PhD}$ students in integrative projects, therefore, frequently lack the support and security offered by a 'home' discipline. Supervisors may only to a minor degree substitute for this lack because they are to some degree also bound to disciplinary structures.

Supportive infrastructures that can facilitate sufficient exchanges on the research subject and provide an adequate and trustful social sphere are essential for integrative research. Only then can $\mathrm{PhD}$ students profit from each other's experiences and learn from their fellow PhD students, who might suffer from similar circumstances. One participant in the $\mathrm{PhD}$ master class put this experience like this: "It was great to discover I was not alone”. PhD students demand, appreciate and reward additional investments into supportive environments as two more statements from participants evidence: "The course was great because it allowed us to meet with other people with similar difficulties and to interact with teachers and researchers who have been there for us: helping, answering questions and being ... open (and most of all friendly)"; "It is important that the network be sustained between us”. 


\section{Communicating and publishing effectively}

Effective communication is probably the key to successful integrative landscape research. Many of the problems and difficulties related to integrative research derive from a lack of communication or to less carefully structured communication. Researchers tend to use technical and specific language, abbreviations and jargon when communicating with their peers. Colleagues from the same field of research will understand the message clearly because they know the concepts, theory and methods and they often have read the same literature. In integrative projects this is often not the case. Researchers communicate to colleagues from different disciplines who either do not know the same concepts or use terms in a different way. By definition, in integrative research, scientists are communicating with other project members, and often with stakeholders that operate outside the academic world and are not familiar with the 'scientific method'. Oral presentations, written reports and papers, chairing meetings and personal interactions that consider the different backgrounds of the people addressed will facilitate greater communication and integration. We recommend that $\mathrm{PhD}$ students, supervisors and anybody else involved in integrative $\mathrm{PhD}$ projects allocate enough time, resources and attention to issues of interdisciplinary and transdisciplinary communication. Successful communication explicitly includes publishing, which, in addition to informing others about research results, has a beneficial impact on academic careers.

Another problem in terms of communication is the difficulty to translate specific landscape-research terminology into English (as the international language for scientific communication). Non-native English-speaking students have sometimes enormous difficulties in translating English terms into their language (and vice versa) and to express their thoughts in English. As an example, we can mention the difficulties in translating the meaning of 'landscape qualities'. In English 'quality' is a rather neutral term expressing 'properties', but in many other languages it is translated literally and gets the connotation of quality in the sense of 'good', 'valuable', etc. Given these problems, we recommend training in scientific English and critical translating of terms, in particular when dealing with international projects or landscape experts (which $\mathrm{PhD}$ students will become) moving around more internationally.

\section{Integrative careers - where do they lead?}

Our experiences from this and other recent $\mathrm{PhD}$ courses revealed that $\mathrm{PhD}$ students in integrative landscape research are caught by the demands of taking a research education and needing to fulfil professional goals of solving real-world problems. We see an increasing number of $\mathrm{PhD}$ students moving between landscape research, landscape planning and landscape management, particularly integrative research students. However, there is a gap in the availability of guidelines to help $\mathrm{PhD}$ students determining their career perspectives. At the moment, they are indirectly prepared for both an academic and a non-academic career, with some of the tensions this can create between the requirements of the researcher and those of the practitioner. Consequently, expectations of an education giving career options for either, or both, a researcher and a practitioner are higher than aiming at one of these career perspectives only. We recommend $\mathrm{PhD}$ students to be prepared for making decisions into which career direction their integrative $\mathrm{PhD}$ study should take them, because it is probably 
not realistic to expect a training for both career options can be met within a $\mathrm{PhD}$ study lasting between three and four years.

\section{Conclusion}

We view the long-term career prospects for $\mathrm{PhD}$ students with integrative landscape research experience as good. At the present time, however, the demand for integrative research is not matched by a willingness to support it effectively.

We see PhD students sitting at the forefront of development of integrative research because many large-scale integrative projects place the task of integration on their shoulders. Many times this proves to be too big a challenge to be reached by the students. PhD students with experiences of integrative research, who are capable of combining their special expertise with the necessary breadth to place their knowledge in a broader context, may have good prospects in both the academic and professional job markets. This is because of the inherently broad personal knowledge base built across the disciplinary boundaries, a greater diversity of skills and methods than may be the case in disciplinary studies, and insights that will commonly extend across the natural and social sciences. Such skills are often the requirements of research institutions as well as the non-academic market, with personnel characteristics that span teamwork, project management, presentation abilities, communication proficiency and, of considerable importance, interpersonal skills.

We also recommend keeping up a critical and self-reflective attitude when being involved in integrative landscape research. Integrative research concepts do not necessarily offer the best solutions, and therefore alternative approaches should

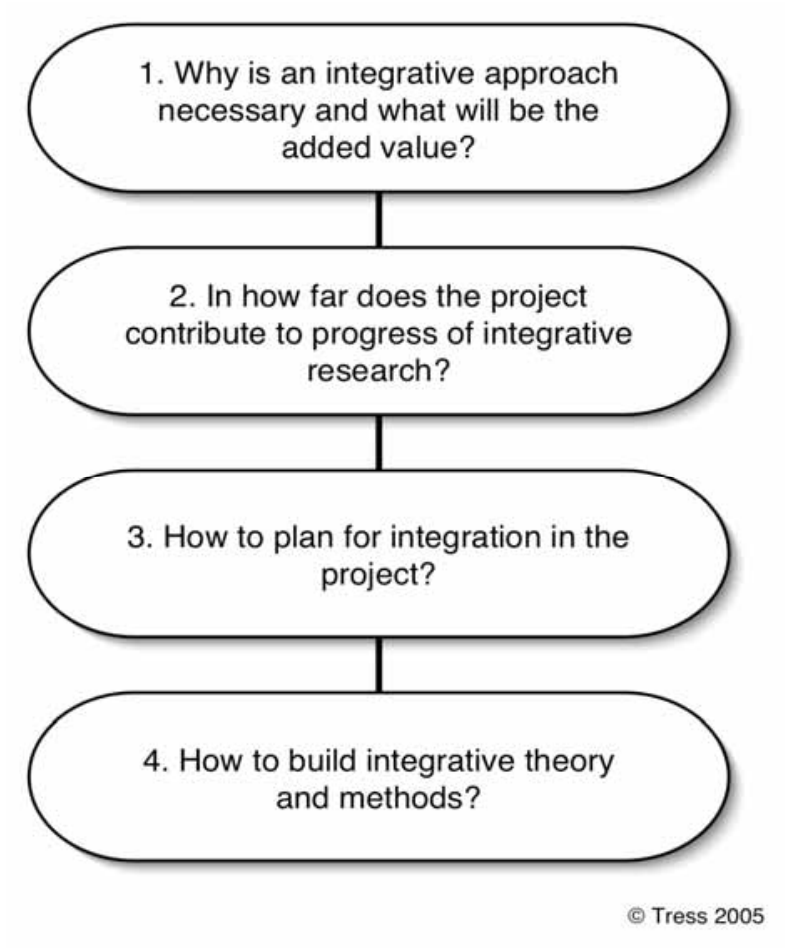

Figure 1. Key questions to be addressed before applying integrative research concepts in $\mathrm{PhD}$ projects 
always be considered. We have formulated four questions that each $\mathrm{PhD}$ student and scholar should able to address before getting involved in integrative research (see Figure 1). When you decide to apply integrative research concepts in a $\mathrm{PhD}$ project, make sure to have the necessary support, resources and time required to address the agreed research goals realistically.

Finally, we emphasize the importance of education for integrative landscape research. When supportive infrastructures and training possibilities are offered, $\mathrm{PhD}$ students in integrative projects no longer need to be pioneers in the integrative research field. We encourage supervisors, institutes and funding agencies to provide the necessary support to enable PhD students, the academic community and society to make full benefit of student motivation to engage in integrative research. Also, $\mathrm{PhD}$ projects that apply integrative research concepts represent an important mode of research training that prepares students for their future careers. We should make the best out of this training and through this provide a good starting point for the students' future career. One student at the $\mathrm{PhD}$ master class has put this into the words: "Hopefully, there is some life after the $\mathrm{PhD!}$ !"

\section{References}

Barthel, S., 2005. Sustaining urban ecosystem services with local stewards participation in Stockholm (Sweden). In: Tress, B., Tress, G., Fry, G., et al. eds. From landscape research to landscape planning: aspects of integration, education, and application. Springer, Dordrecht, this volume, chapter 21. Wageningen UR Frontis Series vol. 12. [http://library.wur.nl/frontis/ landscape_research/21_barthel.pdf]

Drewes, A. and Silbernagel, J., 2005. Setting up an integrative research approach for sustaining wild rice (Zizania palustris) in the Upper Great Lakes Region of North America. In: Tress, B., Tress, G., Fry, G., et al. eds. From landscape research to landscape planning: aspects of integration, education, and application. Springer, Dordrecht, this volume, chapter 27. Wageningen UR Frontis Series vol. 12. [http://library.wur.nl/frontis/landscape_research/ 27_drewes.pdf]

EURAB, 2004. Interdisciplinarity in research. European Union Research Advisory Board.

[http://www.ademe.fr/pcrd/Documents/eurab_interdisciplinarity_research.pdf]

Ferreira, H.S. and Botequilha Leitão, A., 2005. Integrating landscape and water resources planning with focus on sustainability. In: Tress, B., Tress, G., Fry, G., et al. eds. From landscape research to landscape planning: aspects of integration, education, and application. Springer, Dordrecht, this volume, chapter 11. Wageningen UR Frontis Series vol. 12. [http://library.wur.nl/ frontis/landscape_research/11_ferreira.pdf]

Gontier, M., 2005. Integrating landscape ecology in environmental impact assessment using GIS and ecological modelling. In: Tress, B., Tress, G., Fry, G., et al. eds. From landscape research to landscape planning: aspects of integration, education, and application. Springer, Dordrecht, this volume, chapter 24. Wageningen UR Frontis Series vol. 12. [http://library.wur.nl/frontis/ landscape_research/24_gontier.pdf] 
Immink, I., 2005. Towards new policy arrangements for river management in The Netherlands? In: Tress, B., Tress, G., Fry, G., et al. eds. From landscape research to landscape planning: Aspects of integration, education, and application. Springer, Dordrecht, this volume, chapter 28. Wageningen UR Frontis Series vol. 12. [http://library.wur.nl/frontis/landscape_research/ 28_immink.pdf]

Jensen, L.H., 2005. Changing conceptualisation of landscape in English landscape assessment methods. In: Tress, B., Tress, G., Fry, G., et al. eds. From landscape research to landscape planning: aspects of integration, education, and application. Springer, Dordrecht, this volume, chapter 12. Wageningen UR Frontis Series vol. 12. [http://library.wur.nl/frontis/landscape_research/ 12_jensen.pdf]

Lewis, J., 2005. Challenges of interdisciplinarity for forest management and landscape perception research. In: Tress, B., Tress, G., Fry, G., et al. eds. From landscape research to landscape planning: aspects of integration, education, and application. Springer, Dordrecht, this volume, chapter 6 . Wageningen UR Frontis Series vol. 12. [http://library.wur.nl/frontis/ landscape_research/06_lewis.pdf]

Macpherson, H., 2005. Landscape's ocular-centrism: and beyond? In: Tress, B., Tress, G., Fry, G., et al. eds. From landscape research to landscape planning: aspects of integration, education, and application. Springer, Dordrecht, this volume, chapter 7. Wageningen UR Frontis Series vol. 12. [http:// library.wur.nl/frontis/landscape_research/07_macpherson.pdf]

McNamara, L., 2005. Water quality modelling for decision-making: the drinking water watersheds of Sydney, Australia. In: Tress, B., Tress, G., Fry, G., et al. eds. From landscape research to landscape planning: aspects of integration, education, and application. Springer, Dordrecht, this volume, chapter 10 . Wageningen UR Frontis Series vol. 12. [http://library.wur.nl/frontis/ landscape_research/10_mcnamara.pdf]

Nimmo, J., 2005. From river to ridge: local governance and the implementation of improved water management. In: Tress, B., Tress, G., Fry, G., et al. eds. From landscape research to landscape planning: aspects of integration, education, and application. Springer, Dordrecht, this volume, chapter 29. Wageningen UR Frontis Series vol. 12. [http://library.wur.nl/frontis/landscape_research/ 29_nimmo.pdf]

Pacha, M.J., 2005. Integration of ecological knowledge at a landscape level for conservation policies in agricultural areas. In: Tress, B., Tress, G., Fry, G., et al. eds. From landscape research to landscape planning: aspects of integration, education, and application. Springer, Dordrecht, this volume, chapter 26. Wageningen UR Frontis Series vol. 12. [http:// library.wur.nl/frontis/landscape_research/26_pacha.pdf]

Pixova, K. and Sklenicka, P., 2005. Applying special heterogeneity indices in changing landscapes in the Czech Republic. In: Tress, B., Tress, G., Fry, G., et al. eds. From landscape research to landscape planning: aspects of integration, education, and application. Springer, Dordrecht, this volume, chapter 25. Wageningen UR Frontis Series vol. 12. [http:// library.wur.nl/frontis/landscape_research/25_pixova.pdf] 
Queiroz, A.I., 2005. Building landscape memory through combined sources: commons afforestation in Portugal. In: Tress, B., Tress, G., Fry, G., et al. eds. From landscape research to landscape planning: aspects of integration, education, and application. Springer, Dordrecht, this volume, chapter 23. Wageningen UR Frontis Series vol. 12. [http://library.wur.nl/ frontis/landscape_research/23_queiroz.pdf]

Ruiz, J. and Domon, G., 2005. Integrating physical and human dynamics in landscape trajectories: exemplified at the Aulnages watershed (Québec, Canada). In: Tress, B., Tress, G., Fry, G., et al. eds. From landscape research to landscape planning: aspects of integration, education, and application. Springer, Dordrecht, this volume, chapter 5. Wageningen UR Frontis Series vol. 12. [http://library.wur.nl/frontis/landscape_research/05_ruiz.pdf]

Sauer, A., 2005. European nature conservation policy: challenges for local implementation in Germany. In: Tress, B., Tress, G., Fry, G., et al. eds. From landscape research to landscape planning: aspects of integration, education, and application. Springer, Dordrecht, this volume, chapter 13. Wageningen UR Frontis Series vol. 12. [http://library.wur.nl/frontis/landscape_research/ 13_sauer.pdf]

Swagemakers, P. and Wiskerke, J.C., 2005. Integrating landscape management and nature conservation in farming systems in the Friesian Woodlands. In: Tress, B., Tress, G., Fry, G., et al. eds. From landscape research to landscape planning: aspects of integration, education, and application. Springer, Dordrecht, this volume, chapter 22. Wageningen UR Frontis Series vol. 12. [http://library.wur.nl/frontis/landscape_research/22_swagemakers.pdf]

Tress, G., Tress, B., Fry, G., et al., 2005. Trends in landscape research and landscape planning: implications for PhD students. In: Tress, B., Tress, G., Fry, G., et al. eds. From landscape research to landscape planning: aspects of integration, education, and application. Springer, Dordrecht, this volume, chapter 1 . Wageningen UR Frontis Series vol. 12. [http://library.wur.nl/frontis/ landscape_research/01_introduction.pdf]

Tveit, M.S., 2005. Nature meets aesthetics on cultural grounds: a multidisciplinary study of grave mounds in Norway. In: Tress, B., Tress, G., Fry, G., et al. eds. From landscape research to landscape planning: aspects of integration, education, and application. Springer, Dordrecht, this volume, chapter 20. Wageningen UR Frontis Series vol. 12. [http://library.wur.nl/frontis/ landscape_research/20_tveit.pdf] 